\title{
Implementation Challenges of Performance Management System in the South African Mining Industry \\ Rankadimeng Percy Job Seotlela
}

MBA Graduate School of Business \& Government Leadership, North West University - Mafikeng Campus, South Africa

\section{Ogutu Miruka}

Corresponding Author: Associate Professor, Graduate School of Business \& Government Leadership, North West University - Mafikeng Campus, South Africa

Email:mirukaco@gmail.com

\section{Doi:10.5901/mjss.2014.v5n7p177}

\section{Abstract}

This study looked at the general understanding of employees regarding PMS, planning prior to implementation of the system, challenges encountered during implementation and general employees perceptions. Implementation of PMS is seen as an efficient vehicle to successfully deliver on the strategic objectives and goals for many organisations. However, various studies conducted on the implementation of any new system or change initiatives revealed that it leads to challenges for many organisations. This study has investigated implementation challenges encountered during the implementation of PMS. The researcher used single method qualitative case study approach. Primary data was collected through key informants and focus groups interviews and secondary data through internal documents analysis. The researcher used non-probability quota sampling in order to select 24 participants for the 4 focus groups. Senior managers were also interviewed as key informants. The data gathered was analysed against literature reviewed. The study identified various challenges and key factors that were negatively impacting on the successful implementation of PMS. The researcher has established that that the major hindrance regarding successful implementation of PMS was failure from the management to start with change management process and training of employees prior to implementation of the system.

\section{Introduction}

The business world is changing at an ever increasing pace. Just maintaining the current performance of the business is not enough to survive in the $21^{\text {st }}$ century and beyond. Companies must consistently and critically review their performance management systems and take drastic action when necessary to address the identified deficiencies.

The company where the study was conducted implemented Performance Management System (PMS) with intentions of monitoring, reviewing, assessing performance, developing underperformers, and recognising and rewarding good performance. The potential value of using PMS as a tool to manage and measure both employee and organisational performance depends largely on the quality of how the system is implemented. As a result, an implementation of such a system is of critical importance to the success factor in the future of any organisation. Well designed and implemented PMS has positive impact on the overall performance and financial results of the organisation. According to Pulakos (2009:3), performance management system is the most difficult system to implement in organisations.

This research focuses on the challenges encountered by during implementation of its Performance Management System. It strives to investigate challenges encountered and possible solutions on how to overcome them. According to Cooper (2008:2), poorly designed and implemented performance management systems can have disastrous consequences for all those involved. This is further supported by Pulakos (2009:5) as he states that performance management done or implemented poorly will have significant negative consequences for organisations, stakeholders, managers and employees.

Performance management system is seen as an efficient vehicle to successfully deliver on the strategic objectives and goals of organisations. With the move by most organisations from customary performance appraisals to the implementation of PMS, organisations had to face challenges attributed to change. In order to successfully implement and practice efficient and effective PMS, the knowledge of the major challenges associated with effective implementation 
and practice should not be left to luck.

\subsection{Key Focus of the Study}

The potential value of using PMS as a tool to manage and measure both employee and organisational performance depends largely on the quality of how the system is implemented. As a result, an implementation of such a system is of critical importance to the success factor in the future of any organisation.

If PMS is properly developed and implemented in an organisation, sustainable improvement in organisations performance, change in developing a more performance oriented culture, enhancing motivation and commitment of employees, developing team work and open culture to discuss work related issues, and empowering individuals to provide their talent for the success of the organisations' objectives are major benefits expected to be achieved (Armstrong and Baron, 2006). On the other contrary, they argue that, if the system development and implementation are misguided, then all efforts will remain futile exercise, which could lead to wastage of resources.

The key focus of this study was to investigate challenges encountered during implementation of PMS in an organisation and the findings will add significant contribution to the existing body of knowledge.

\subsection{Background to the Study}

This qualitative, explanatory case study was conducted in a health service institution which is wholly owned by a Gold mining company, in the Vaal River region of the North West province. The implementation of the PMS was preceded by the use of performance appraisals as a tool used to measure employee's performance within the organisation. Spansberg and Theron (2001) support the notion that performance appraisal as a process failed, hence the development of the PMS.

The main objective was not to analyse a specific area of performance management, but rather to critically assess implementation challenges of the entire PMS and then perform an evaluation on the subject area. The researcher also scrutinised the successful areas of implementation and highlighted any possible shortcomings identified during the study. It is of the researcher's opinion that if attention is not paid to the challenges encountered during implementation, they may have a damaging impact on employee performance and could ultimately have a negative impact on the overall company performance management and achievement of critical strategic objectives.

\subsection{Trends from the Literature}

Implementing a well-designed PMS has many advantages. From perspective of employees, a good system increases motivation and self-esteem, helps improve performance, clarifies job tasks and duties, provides self-insight and development opportunities, and clarifies supervisors' expectations (Cooper, 2008). However, from the perspective of managers, good systems allow them to gain insight about employees, allow for more fair and appropriate personnel actions, help them to communicate organisational goals more clearly, let them differentiate good and poor performers, and help drive organisational change (Cooper, 2008).

Various factors can constitute a draw back in the implementation of PMS (Ammons, 2001). This is supported by Cooper (2008) as he stated that poorly designed and implemented PMS can have disastrous consequences for all those involved. Therefore it is imperative that all role players ensure effective and successful implementation of the system for the betterment and benefit of the organisation and employees.

On the other hand, Pace (2011) argues that most critical performance management implementation challenges are related to poor executive engagement. He further states that organisations will have better business results when senior management / leaders hold direct reports responsible for supporting their employees during implementation of the system.

Previous studies indicate that the weakness in a PMS arise primarily because the system was poorly designed, training and communication has not been transferred into the organisation to support its implementation (Watkins \& Leigh, 2012).

According to de Waal \& Counet (2009), implementing a new PMS, which makes performance management of everybody in the organisation much more transparent, can cause resistance amongst organisational members because they feel threatened by the new system. Rees \& Porter (2002) suggest that, it may be positively dangerous simply to copy schemes used in other organisations, and worse still to introduce a scheme simply because it is the managerial fashion (Rees \& Porter, 2002). Hence Watkins \& Leigh (2012) recommends that careful attention should be paid to 
communicate the benefits of the PMS to employees when it is introduced to counter any resistance to change.

\subsection{Research Objectives}

The primary objective was to investigate challenges encountered during PMS implementation. This was primarily to enable the researcher to gain an in-depth understanding of challenges encountered, in order to revise where necessary and advice on areas of improvement. The objective of the study was achieved by means of a qualitative research approach through pursuance of the following secondary objectives:

- Gaining an in-depth understanding of the theory and different models of PMS through the review of relevant literature.

- Gaining an understanding of performance management development process and its inherent requirements.

- Identifying main challenges that were encountered during implementation and ways of mitigating those challenges.

- Integrating results from the study and presenting a group perspective of employees' experiences and perceptions by means of focus groups and key informants interviews data-gathering methods.

\subsection{Contribution to field}

This study has contributed to the existing body of knowledge regarding challenges encountered during the implementation of PMS in an organisation. By virtue of the researcher having adopted a single case study approach and using mainly focus groups interviews as the main source of primary data, the results of this research cannot be generalised to the wider population, but the findings will definitely assist in the development and successful implementation of PMS in some organisations. Therefore, the results of this study can be used as a guideline as it contains important discussions on the topic of development and implementation PMS.

\section{Literature Review}

Managing employee performance is an integral part of the work that companies need to monitor continuously. PMS has become more important in recent years because managers, be they in the public or private sector, are under constant pressure to improve the performance of their organisations.

Armstrong (2006) argues that PMS exists to align employee performance with company's needs and to ensure that the effort is not only sustained and improved, but that it also provides the results required at every level to fulfil the company strategy and objectives, thus safeguarding and increasing shareholder value. Hence employee performance or the lack thereof, is very much important because it has a profound effect on both the achievements of strategic objectives/goals and the overall performance results of any organisation. Many studies revealed that performance management can assist organisations to discover gaps in their system and to take corrective actions when the need arises to address identified deficiencies.

The performance of an organisation as a whole depends largely on the performance of individual employees, hence it is critical to ensure effective implementation of PMS. It is true that high performing organisations contribute immensely to the development of its employees which subsequently leads to increased motivation and productivity (performance) among employees.

\subsection{Implementation challenges of PMS}

The subject of performance management has attracted a lot of attention, mainly from academics. As indicated earlier, there is a view that an effective implementation of performance management requires best performance management implementation model and practice. However, other researchers contends that performance management models and best practices depend largely on the management, employees and all the role players unequivocally showing support and commitment for the implementation of successful PMS.

Developing and implementing new PMS is major organisational intervention and change strategy. It requires adjustments in other management activities and practices, because the impact of these changes can be a cause for resistance to implement the system. 


\subsection{Senior and Line Management Commitment}

According to Pace (2011), most critical performance management implementation challenges are related to poor executive engagement and execution. It is utterly useless to have a well-developed PMS without commitment from the management team. If senior and line management do not show commitment to the implemented PMS, the employees will also not take it serious. Line managers need to show a real sense of ownership during implementation of PMS.

Nel et al. (2001) suggest that in order to ensure effective implementation of PMS, this must be line driven rather HR department driven. This is further supported by Armstrong \& Baron (2005) who are of the opinion that performance management is owned and delivered by line managers. It is not a personnel technique run by the HR department. As a result, if line management buy-in and commitment is not dealt with, performance management implementation is doomed to fail. However, in a study conducted by Ngcelwane (2008), there is a widespread perception that PMS implementation is owned by Human Resources Department, with line managers excluded from the process.

\subsection{Lack of Knowledge and Skill}

Watkins \& Leigh (2012) argues that the weakness in a performance management system arise primarily because the PMS is poorly designed or training on the PMS has not transferred into the organisation to support its implementation. Regular rather than a once off communication should be driven from the highest offices and supported by the communications department using every possible vehicle within the organisation's communication infrastructure. Davis \& Rogers (2006) argue that it is critical that the organisation develop a pre-launch, launch, and post-launch communication plan. Communications should be crafted to build enthusiasm, understanding, and commitment by continually explaining the benefits of using the system to employees, to leaders, and to the organisations

\subsection{Resistance to Change}

As indicated above, implementing a PMS, which makes performance of everybody in the organisation much more transparent, can cause resistance amongst organisational members. Various authors acknowledge resistance in any change initiative as a normal human behaviour that must be overcome for the PMS initiative to succeed. The most critical and frequently experienced challenge in the development, implementation and maintenance of PMS within organisations is probably organisational culture (Markus, 2004). The traditional organisational culture is a significant obstacle to effective performance management.

Previous studies have revealed that when implementing PMS, there is typically some form of cultural or attitudinal resistance during the process of trying to achieve organisation wide buy-in for the system. Cultural challenges are typically the result of people's inherent resistance to change. Employees may feel threatened by new system being implemented, or may have become paranoid as a result of the failure of previous system. Dealing with cultural challenges effectively necessitates buy-in from the very top management of the organisation.

An effective PMS actively involves employees throughout the performance cycle, hence Kotter (2007) asserts that continuous communication is very much important to reinforce the message so that there is no delusion as to what brought about the need for PMS. In any implementation of a process intended to change behaviour, like with PMS, it is crucial to develop both the confidence and the competence of all key role players around fulfilling their roles.

\subsection{Evaluating Performance}

Traditionally, performance evaluations are an annual or semi-annual event that at times can be seen by employees as routine and insignificant. Evaluating performance competencies is usually the most difficult part of performance management. Line managers are generally less comfortable discussing and giving feedback on behaviours, and because they are more subjective and less quantifiable than objectives, as a result managers tend to avoid this area.

Sunlin (2008) states that to evaluate performance in dimensions requires collecting performance data. The accuracy of the evaluation is dependent on the quality of the data gathered. Performance data is obtained through observations of behaviours or, less ideally, by inferring behaviours through knowledge of results. Another important element in successfully measuring dimensions is describing appropriate key actions/behaviours in the performance plan. These not only set expectations, they are critical in helping classify behavioural examples into dimensions and then evaluating performance. According to Watkins \& Leigh (2012), a behaviour based evaluation system reviews an employee's job activities and rewards an employee based on work effort. 


\subsection{Keeping the System Active}

Previous studies revealed that the greatest challenge for many organisations is keeping the performance management system viable after the first year or two. Sunlin (2008) refers to a 1995 survey where it indicated that $44 \%$ of 218 companies with performance management systems had changed systems in two years and that another $29 \%$ expected to do so. Other studies have shown that most organisations replace their system on average every 3-4 years.

It is important to periodically monitor the system, revise portions of it when necessary, and refresh people's interest in the system. Too often, organisations ignore the system and then are faced with completely dismantling it after the system has become woefully out of step with the times, or employees mistrust its use.

\subsection{Linking Job Descriptions to Performance Management}

Cooper (2008) states that the tasks and key result indicators (KRI) included in individual job descriptions must be congruent with the organisation and unit's strategic plans. In other words, job descriptions should include activities that, if executed well, will help fulfil the mission and vision. Job descriptions detached from strategic priorities will lead to performance evaluations focused on behaviours and results that are not central to an organisation's success.

The managers need to ensure that the job descriptions and objectives are aligned with the organisation's strategic objectives. Objectives should be based on the individual's job description and should be achievable, with expected outcomes, performance standards and time-scales linked to each objective. In setting objectives, it is important for the supervisor and the employee to understand key characteristics of objectives.

Sunlin (2008) is of the opinion that performance plans in a good performance management system will maintain a current view of the expectations and accountabilities for an individual or team. On the other hand, Schraeder \& Jordan (2011) argue that the overall effectiveness of performance management programs can be improved by ensuring that key performance expectations are delineated in employee job descriptions and are reflected in methods used to measure performance. They both argue that the idea is to delineate the expectations clearly related to tasks in employee job descriptions and then measure them on a concurrent basis as a component of the PMS. Hence, having direct links between job descriptions and individual performance plans and appraisals is very critical. However, the most common challenge is keeping job descriptions up to date.

\subsection{The implementation requires more time and effort than expected}

Implementation of a PMS takes a considerable period of time, after which the organisation has to start learning the new system which also takes time. During this entire period, commitment and support from management is required otherwise the PMS can be seen as "flavour of the month" by organisational members.

\subsection{Understanding of available literature on existing perceptions regarding PMS}

Rousseau \& Greller (1994) cited in Nyembezi (2009) state that PMS practices can be seen as indicators of an organisation's intentions toward its employees, and are interpreted as such by individual employees. However, employees do not necessarily perceive such indicators similarly or react to them in a similar manner. The impact of PM practices on employee's obligations and performance depends on employee's perception and evaluation of these practices (Guest, 1999). Perceptions and attitudes may intervene and moderate the relationship between PMS practices and employee's performance-related behaviour.

According to Nyembezi (2009), variation may exist in employee's perceptions of PMS practices even when, in objective terms, what is offered to different employees is very similar. Individual differences in perceptions and reactions to what the organisation has to offer might for instance, follow from an employee's previous experience as well as his/her beliefs. Krell (2011) suggest that the way PMS is perceived by the employees, especially if there is an element of biasness during the implementation process, can degrade the effectiveness of a crucial business process-one directly related to employee performance management.

Latham \& Mann (2006) states that effective performance management systems must be perceived as fair, and that the factors contributing to fairness include distributive fairness, procedural fairness and voice. Distributive and procedural fairness are associated with both task and contextual performance (Cropanzano, Bowen, \& Gilliland, 2007). The final factor, involves employee's belief that their views are taken into account (Latham \& Mann, 2006) and can involve participation in the performance management implementation process. 
Latham \& Mann (2006) suggest that employees often believe that PMS is implemented for all the wrong reasons, by the management, that is, the management is trying to use this process as a way to hold them account and subsequently much easier to discipline them, hence the perception that it is not fair. This perceived lack of procedural fairness can have ranging negative implications for organisations. According to Cawley, Keeping \& Levy (1998) cited in Aguinis (2005) they did discover that participation by employees in the performance management process is associated with higher perceived fairness, satisfaction and motivation to perform better.

Guest (1999) cited in Selden \& Sowa (2011) argues that the impact of performance management, depends upon the employee's perception and evaluation, prompting the need for the management to recognise the crucial role of employee perceptions and to incorporate them into the analysis and construction of performance management in these organisations.

According to Brand \& Pretorius (2003), there seems to be a strong relation between employee's perceptions regarding the following aspects:

- The degree to which management communicates with employees regarding the organisation's vision and objectives and employee's perception of their involvement in PMS development and implementation in the organisation. It is an attempt to change emotions, beliefs, values and attitudes by increasing the information flow to people, a task accomplished by explaining policies, instituting staff meetings, keeping an open door and other such communication mechanisms

- The extent to which training in the organisation empowers employees to effectively define jobs and performance standards in relation to PMS

- The level at which training assist supervisors to provide the right feedback on performance areas that need improvement and perceptions of management's commitment to and involvement in the successful implementation of the PMS.

- The degree to which training enables supervisors to address performance management problems and how well supervisors utilise the system of performance management as an aid to development in the organisation.

- The extent to which supervisors, during training, are given the opportunity to exercise their skills and their perceived ability to address performance problems.

- The scope to which supervisors, during training, are given the opportunity to exercise their skills and employee's perceptions of the extent to which supervisors learn to determine how well they (employees) apply their skills in the workplace

\section{Research Design}

Yin (1994) describes the case study as an empirical inquiry that investigates contemporary phenomena within their real life context when the boundaries between phenomena and context are not clearly evident and in which multiple sources of evidence is used. The reason for utilising the case study methodology is that it allowed for an in-depth, detailed understanding of a specific phenomenon within an enclosed system.

\subsection{Research Approach}

The study was conducted by means of an explanatory, qualitative case study which provided for collection of data through focus groups and key informants interviews. This approach has allowed the researcher to see things from the participant's frame of reference. Qualitative research focus on the interpretation of the action or representation of meaning created by individuals (Clarke, 2011).

\subsection{Research Strategy}

This is an explanatory, qualitative case study aimed at seeking answers to research questions raised in the study. Zimkund, Babin, Carr \& Griffin (2011) refer to qualitative research as research that addresses objectives through techniques that allow researchers to provide elaborate interpretations of phenomena without depending on numerical measurement.

The type of research that was undertaken in this project is applied research. Applied research is described by Clarke (2011) and Fox \& Bayat (2011) as research aimed at finding a solution or answer to a specific problem or question. 


\subsection{Research Method}

This study was confined to the employees of a Health Service organisation in the North West province, through quota sampling as a technique to select participants / sample, which is a non-probability group. One advantage why the researcher opted to use this type of sampling approach is because, It is quite quick, easy and cheap, but is equally as representative as other sampling types.

\subsection{Research Setting}

Permission was requested from senior management and line managers, and the venue was secured inside participants' workplace for their convenience, with assistance from Human Resources Department officials. Appointments were also arranged and confirmed a month before the discussion to allow participants enough time to arrange their diaries and be able to attend the discussions.

\section{Sampling}

The population in this study is the Health Service permanent employees, from senior and middle management, HR department (custodian of PMS), nurses and allied health professionals. However, data can only be obtained from a sample of the above population.

The researcher selected 24 participants in 4 groups for the focus groups. The first group consisted of Nursing Unit Managers, the second group of Allied Healthcare professional Unit Mangers and other support staff like finance and human resources, third and fourth groups of professional nurses. The selection was based on the level of years of service and experiences participants have in the organisation.

\section{Data Collection}

The researcher used unstructured interviews in order to conduct focus groups and key informants interview to collect primary data, an analysis of existing documents to gather secondary data and observation. The researcher's questions were thus directed at the participant's experiences, perceptions feelings and convictions regarding the organisations performance management implementation challenges. The focus was on participant's first experience of the organisation's PMS implementation challenges.

\subsection{Recording of Data}

The discussions were recorded on a digital recorder, transcribed and analysed later by the researcher. The group members were informed beforehand about the recording and their consent was obtained before the discussions commenced. Should they feel uncomfortable at any given point in time during the discussions, they were allowed to indicate this to the researcher.

\subsection{Ethical considerations}

Participants were ensured complete voluntary participation in the study. No one was coerced to participate in the study unless informed consent has been obtained prior. Over and above voluntary participation, participants were informed of their right to discontinue / exit study at any point should they wish to do so without fear. The researcher further guarantees confidentiality and anonymity of the subjects, no personal information was collected.

\subsection{Data Protection}

All data collected will be used purely for the purpose of this study and will be securely stored on a personal laptop of the researcher which is password protected. All data folders were also password protected as an additional measure to ensure complete security. Under no circumstances was any part of the data accessed or accessible to any other persons 


\section{Potential Benefits and Hazards}

The company could benefit from taking note of the research findings and consider implementing some if not all the recommendations suggested by the researcher. The participants were in no way exposed to any form hazards. Complete confidentiality and anonymity was guaranteed to all those who participated in the study and no data (raw) will be disclosed to anyone, including the company's management team.

\section{Validity}

According to Struwig and Stead (2010:136) validity refers to the extent to which a research design is scientifically sound or appropriately conducted. Validity can be enhanced by means of triangulation, which implies that there must be various data sources or various research methods. Hence the researcher used different approaches of data collection, i.e., from primary sources through key informants interviews, focus group interviews (different functional categories of employees), observation and analysis of documents for secondary data. The utilisation of these methods assisted the researcher to triangulate data which improved the validity of collected data. To this end the researcher ensured that data collected is corroborated by three different sources, key informants, focus groups (interviewing of different functional categories), observation and secondary data (documentary evidence) which provides validity to the research in terms of triangulation (Welman \& Kruger, 2001).

\section{Reliability}

Windgardner (2001) refers to reliability as the extent to which other researchers would arrive at the same results (credibility) if they studied the same case using the exactly the same procedures. As suggested by Smith (2003), in order for the research to be credible, it should clearly reiterate the views of the participants and this can be achieved through triangulation of data. Credibility was assessed by noting whether the written records, interviews and participant observation all lead to similar conclusions being drawn.

\section{Findings}

The data collected was done with the specific reference to the four research questions. After having carefully considered all data collected, the study findings were summarised as follows:

\subsection{Understanding of PMS}

- Better understanding displayed by the management representation regarding this concept

- Little or even lack of understanding by lower category employees

- Satisfactory level of the performance management processes within the organisation, even though there seems to be confusion regarding the two concepts: Contract and contact sessions

\subsection{Planning prior to implementation}

- Change management and pilot testing not done prior to the implementation of the system

- Capacity building of Unit Managers prior to implementation in order to improve their level of management skills and prepare them for the system.

- Insufficient to lack training regarding PMS

- Poor communication and lack of information by the line managers

\subsection{Implementation Challenges}

- Resistance to change

- In-adequate training of line manager and lack thereof to the lower categories

- Limited or little understanding of the concept PMS

- Lack of adequate support from HR department 
- Non-availability of job descriptions for newly created positions

- Competency level of line managers

\subsection{Employees' perceptions}

- The perception from managers is that the system allows for transparency which is contrary to what is perceived by other focus groups members in that, the system is not transparent. They think the management implemented this system because they have ulterior motives.

- Perception from lower category that the mangers keep most of the information to themselves. This indicates a gap that exists between line managers and employees.

- Another perception from the lower category focus groups is that something went wrong from the onset of implementation of the system.

- The managers perceive the system as adding value which is also contrary to the perception of lower category focus groups. They don't see system as adding value because recognition is the same for everyone, irrespective of individual performance.

\section{Findings and Practical Implications}

The main objective of the study was to investigate the challenges encountered at during implementation their Performance Management System. The results show that the challenges did exist to a certain extent and are viewed from different angles by both the management representatives and lower category (ordinary) employees who were interviewed. Lower level category of employees interviewed during focus groups discussions, displayed a general feeling of dissatisfaction towards the way the system was implemented. There seem to be a gap that exists between the management and employees. But on the contrary, even though the management indicated existence of challenges during implementation process, they displayed a very positive attitude towards the system.

This study revealed inconsistencies regarding training and communication related challenges. The study also revealed that the management representative who either participated as key informants or in Unit Manager's (UM) focus groups displayed a general satisfactory level of understanding of the PMS. However, of concern is what was displayed by other employees from other focus groups regarding their level of understanding of PMS. These employees displayed little or limited understanding of what PMS is all about, hence resistance to change and difficulty in getting buy-in from some of the employees. This can be attributed to lack of training that the study revealed it was not done or only done up to certain levels of management. Besides lack of understanding displayed by this group, they however showed a better understanding of the organisation PMS process.

The other important aspect drawn from the findings is failure on the side of management to implement management of change in relation to PMS. Failure to implement change management process can also lead resistance change and limited understanding. The benefit that can be derived from this change management is basically education, induction, information sharing and preparation of employees regarding eminent change and implementation of the new system.

On the positive side, the study revealed commitment of the management team, especially senior management, regarding PMS. Lack of support from HR raised a concern to the researcher, because HR is the custodian of this process. But, line management needs appreciate that, even though this process belongs to HR, they are just there to give guidance and support and to do everything for them. They, line managers, remain responsible for the day to day management of the whole performance management process.

\section{Limitations of the Study}

By virtue of the researcher having adopted a single case study approach, results will not be generalizable beyond the specific population from which the sample was drawn.

\section{Recommendations}

In view of the research findings, data analysis in relation to the reviewed literature, the researcher decided to divide the recommendations into two distinct types: recommendations for action or practice. 
The management must initiate adequate training regarding performance management and ensure that it is provided to all employees in all levels within the organisation. This training will definitely improve the current level of understanding regarding performance management amongst employees. Such training is vital for the system to be understood in this context.

Capacity building of all lower level management should continue and an assessment implemented in order to evaluate progress made and where there is need for further improvement. The researcher believes that the managers can also benefit from communication skills course. This course might assist with improving their communication skills and enhancing their ability to communicate and share information openly and freely.

The gap between management and employees needs to be bridged, so that employees can view their management from a different perspective than they currently do. Their attitude towards management needs to be changed. It is also the management responsibility to ensure that they assist employees to dispel their negative perceptions and attitude towards.

The company needs to carefully consider implementing change management because this will most probably address most challenges identified in the study. Implementation of the new PMS is major organisational intervention and change strategy, which requires some adjustment in other activities and practices within the organisation. In order to ensure effective implementation of the organisation's PMS, change management needs to be done.

\section{Conclusion}

The main objective of this study was to investigate implementation challenges of PMS. The researcher used qualitative, explanatory approach and collected data through focus groups, key informants and analysis of existing documents. This objective could only be achieved by answering the four research questions posed in relation to the research problem. According to the researcher, this was realised.

It is recommended that a more comprehensive exploratory study should be undertaken on a wide scale, for developing a more comprehensive research study that will allow for generalisation of the research findings.

It would appear that the major hindrance regarding successful implementation of PMS was failure from the management to start with change management, communication and training of employees about the whole process. This could have ensured buy-in from the employees

Beside all the challenges raised and the negative perceptions alluded to by members of the certain focus groups, there is a general consensus from all those interviewed that it is possible to ensure that the system is successfully implemented if what has been raised as concerns and suggested as solutions can be addressed by the management.

\section{References}

Aguinis, H. (2009). Performance Management. Edenburgh Business School. United Kingdom: Heriot-Watt University.

Ammons, D.N. (2001). Municipal benchmarks: assessing local performance and establishing community standards ( $2^{\text {nd }}$ ed.). California: Sage Publications

Armstrong, M., \& Baron, A. (2005). Managing Performance: Performance Management in Action. London: Chartered Institute of Personnel and Development (CIPD).

Armstrong, M., \& Baron, A. (2006). Performance Management. Mumbai: Jaico Publishing House.

Armstrong, M., (2006). Performance Management: Key Strategies and Practical Guidelines (3rd ed.). London-UK: Kogan Page.

Brand, H.E., \& Pretorius, O.J. (2003). "Employees perceptions of Performance Evaluation in the Manufacturing Industry". SAJEMS NS, 6(3), 577-589.

Clarke, A. (2011). An Invitation to Social Research: How it's Done. (4th ed.) USA: Wadsworth Cengage Learning.

Cooper, J. (2008). Performance Management. Edinburgh Business School.

Cropanzano, R., Bowen, D. E., \& Gilliland, S. W. (2007). The management of organizational justice. Academy of Management Perspectives, 21, 34-48.

Davis, P., \& Rogers, R.W. (2006). Getting the Most of you Performance Management System. White Paper, 1-5.

de Waal, A.A., \& Counet, H. (2009). Lessons learned from performance management systems implementations: International Journal of Productivity and Performance Management Emerald Article, 58(4), 367-390.

Fox, W., \& Bayat, M.S. (2011). A Guide to Managing Research. Cape Town: Juta.

Guest, D.E. (1999). Human Resource Management: The Workers Verdict. Human Resource Management Journal, 9, 4-10.

Krell, E. (2011). How the "Moneyball" Approach Could Be Applied to HR Methods: HR Magazine. 15.

Kotter J.P. (2007). Leading Change, Why Transformation Efforts Fail. Harvard Business Review

Markus, L.H., (2004). Performance Management - Problems and Potential. e-HR Systems. Centranum Ltd.

Latham, G.P. \& Mann, S. (2006). Advances in the science of performance appraisal: Implications for practice. International Review of 
Industrial and Organizational Psychology, 21, 295-337.

Nel, P., Werner, A., Poisat, P., Sono, T., Du Plessis. A., \& Ngalo, O. (2011). Human Resources Management (8th ed.). Oxford University Press: Cape Town.

Ngcelwane, M.J. (2008). A critical Assessment of the Implementation of Performance Management in the Nelson Mandela Bay Municipality, Rhodes Investec School.

Nyembezi, V. (2009). Development of a Performance Management System for the SABC. Nelson Mandela Metropolitan University Business School.

Pace, A. (2011, October). The Performance Management Dilemma. Intelligence // Human Performance. 12.

Rees, W.D., \& Porter, C. (2002). "Management by panacea-the training implication". Industrial and Commercial Training, 34(6), 228-230.

Schraeder, M., \& Jordan, M. (2011). Managing Performance: A practical perspective on employee performance. The Journal for Quality and Participation. 4-10.

Selden, S., \& Sowa, J.E. (2011). Performance Management and Appraisal in Human Service Organizations: Management and Staff Perspectives: Public Personnel Management. 40(3), 251 - 264.

Smith, C. (2003). Document Analysis. Grahamstown: Department of Education, Rhodes University.

Spangenberg, H.H., \& Theron, C.C. (2001). Adapting the system model of performance management to major changes in the external and internal organisational environments. South African Journal for Business management. 32(1), 35-46.

Struwig, F.W., \& Stead, G.B. (2010). Planning, designing and reporting research. Cape Town: Maskew Miller Longman (Pty) Ltd.

Sunlin, R. (2008), Common performance management challenges: Retrieved August 28, 2012 from http://www.workinfo.com/free/downloads/135.htm.

Watkins, R., \& Leigh, D. (2012). Improving Performance in the Workplace: Selecting and Implementing Performance Interventions. 2. Pfeiffer: San Francisco.

Welman, J.C., \& Kruger, S.J. (2001). Research Methodology. (2nd ed.). Cape Town: Oxford University Press Southern Africa.

Windgardner, K.E. (December, 2001). The Case Study Method of Scholarly Research. Retrieved November 10, 2013. http://www.phinished.org/links/showlink.php?s=3f9dea3411970ef2817ae5499512b632\&l=1093\&linkurl=https://uascentral.uas.ala ska.edu/onlinelib/Summer-2007/PADM635-JD1/Windgardner__case_study_research.pdf

Yin, R.K., (1984). Case Study Research: Design and Methods. Beverly Hills, California: Sage

Zimkund, W.G., Babin, B.C., Carr, J.C., \& Griffin, M. (2010). Business Research Methods. South Western, Cengage Learning: Canada. 